\title{
Overcoming CD4 deficiency to induce long-lived memory CD8+ CTL

\author{
SangKon Oh${ }^{1}$, Liyanage P Perera ${ }^{2}$, Thomas A Waldmann ${ }^{2}$ and \\ Jay A Berzofsky*1
}

Address: ${ }^{1}$ Vaccine Branch, NCI, NIH, Bethesda, Maryland 20892, USA and ${ }^{2}$ Metabolism Branch, NCI, NIH, Bethesda, Maryland 20892, USA

* Corresponding author

from 2006 International Meeting of The Institute of Human Virology

Baltimore, USA. |7-2I November, 2006

Published: 21 December 2006

Retrovirology 2006, 3(SuppI I):SI7 doi:I0.II86/I742-4690-3-SI-SI7

(C) 2006 Oh et al; licensee BioMed Central Ltd.

One critical hurdle for therapeutic HIV vaccines is the deficiency of $\mathrm{CD}^{+} \mathrm{T}$ cell help during HIV infection. CD4 ${ }^{+}$ $\mathrm{T}$ cell help has been shown to be necessary for induction of long-lived memory $\mathrm{CD}^{+}$cytotoxic $\mathrm{T}$ lymphocytes (CTL), and when $\mathrm{CD} 8^{+} \mathrm{T}$ cells are primed in its absence, they are susceptible to TRAIL-mediated death during secondary stimulation. We have found that IL-15 expression by a vaccine vector allowed induction of longer-lived, higher avidity memory CTL. We also observed that CD40L, a molecule by which helper T cells mediate help, induces dendritic cells to secrete IL-15. We therefore hypothesized that one mechanism by which $\mathrm{CD} 4^{+} \mathrm{T}$ helper cells induce longer-lived memory CTL may be to stimulate IL-15 production by the dendritic cell presenting antigen, and that therefore, IL-15 might overcome the need for $\mathrm{CD} 4^{+} \mathrm{T}$ cell help. We have now tested this hypothesis by demonstrating that immunization of CD4depleted mice with a recombinant vaccinia-HIV vaccine vector expressing IL-15 induced long-lived memory CTL, whereas immunization of the depleted mice with a recombinant vaccinia-HIV vector not expressing IL-15 resulted in short-lived CTL that disappeared within two months. Further, CTL induced with the IL-15-expressing vaccine were resistant to TRAIL-mediated death on secondary stimulation, whereas those induced without IL-15 underwent apoptosis. Resistance was associated with upregulation by IL-15 of anti-apoptotic Bcl-XL and downregulation of Bax, a downstream transducer of the TRAIL death signal. These findings help explain the role of helper $\mathrm{T}$ cells in inducing long-lived memory CTL and provide a practical approach to overcome the deficiency of $\mathrm{CD} 4{ }^{+} \mathrm{T}$ cell help during HIV infection for induction of CTL with a therapeutic vaccine for HIV, or with a vaccine for other opportunistic infections. 